\title{
Lua: espelho meu, espelho meu, ...
}

\author{
Pedro Mota Machado \\ Instituto de Astrofísica e Ciências do Espaço e Faculdade de Ciências da Universidade de Lisboa \\ machado@oal.ul.pt
}

\begin{abstract}
Moon: mirror, mirror of mine, ... - Using the Moon as if it was a mirror seems a bizarre idea. However, various scientific approaches have resorted to this technique in order to achieve their objectives. The Hubble Space Telescope's observation of the Venus' transit in June 2012 intended to use this method, since direct observation of the Sun was impossible. Among those research projects, several have used the reflection of the light on the Moon, in order to detect evidence of existence of life on Earth from the analysis of the reflection of the terrestrial glow on the lunar surface.
\end{abstract}

U sar a Lua como se fosse um espelho parece uma ideia bizarra. Contudo, diversas abordagens científicas recorreram a este subterfúgio para alcançar os seus objetivos. Para a observação do trânsito de Vénus em junho de 2012, pelo telescópio espacial Hubble, recorreu-se a este método, visto ser impossível uma observação direta do Sol. A análise da reflexão do brilho terrestre na superfície lunar tem também sido utilizada para o desenvolvimento de métodos para detetar evidências da existência de vida na Terra.

No dia 5 de junho de 2012 o planeta Vénus passou em frente ao Sol a partir da linha de visão da Terra. Este fenómeno, denominado trânsito de Vénus, foi acompanhado pelo telescópio espacial Hubble. Atendendo a que o Hubble não pode apontar diretamente para o Sol, usou-se um subterfúgio: utilizou-se a Lua como um espelho. Na realidade, o projeto assentava na reconstrução da frente de onda da imagem do Sol refletida na cratera lunar Tycho (figura 1).

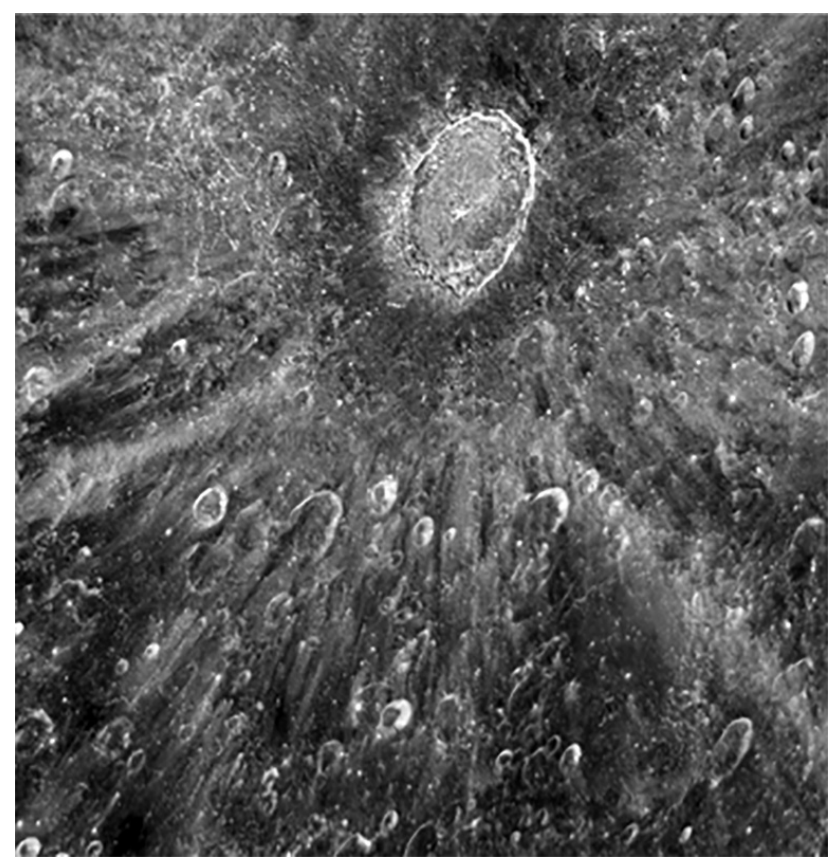

Figura 1 - A cratera lunar Tycho foi observada pelo telescópio espacial Hubble. Esta observação fez parte do projeto de preparação para a observação indireta do trânsito de Vénus em junho de 2012. A ideia base deste projeto era utilizar a imagem do trânsito refletida na Lua, como se esta fosse um espelho. Imagem: http://hubblesite.org/image/3043; créditos da imagem: NASA, ESA e D. Ehrenreich (Institut de Planétologie et d'Astrophysique de Grenoble (IPAG)/CNRS/Université Joseph Fourier).
O método consistiu em selecionar e capturar a fração da luz solar que foi transmitida através da atmosfera de Vénus e que atingiu a cratera Tycho, foi refletida e atingiu o telescópio Hubble. Visto que a interação da luz transmitida com a atmosfera de Vénus deixou a sua marca nessa radiação, como se fosse uma impressão digital dessa atmosfera, foi possível interpretar as consequências da sua passagem pela atmosfera e inferir vários aspetos da atmosfera venusiana, nomeadamente a sua estrutura vertical em função da densidade, o perfil vertical da temperatura, entre outros.

Uma técnica semelhante àquela aqui descrita foi usada no contexto da caracterização da atmosfera de exoplanetas. Essa técnica tira também partido da transmissão da luz da estrela aquando do trânsito de planetas gigantes. Na verdade, a estrutura geométrica do método utilizado para a análise de atmosferas de exoplanetas é análoga à agora usada durante o trânsito de Vénus. A utilização de Vénus como proxy é muito relevante dada a sua semelhança em tamanho e massa com o planeta Terra.

O telescópio Hubble observou a Lua durante sete horas de modo a obter uma linha de base estável e consolidada para comparação com a sequência de observações durante o trânsito de Vénus. Foram utilizados diversos instrumentos do telescópio Hubble (figura 2), como a Advanced Camera for Surveys (ACS), Wide Field Camera (WPC) e o espectrógrafo de imagem do telescópio espacial (STIS). Desse modo foi recolhida uma panóplia de dados quer ao nível de imagem (fotometria), quer a nível espectroscópico, para possibilitar a análise espectral da radiação coletada. A gama de comprimentos de onda sondados compreendeu quer o ultravioleta, passando pelo visível, até ao infravermelho próximo.

A assinatura espectral da transmissão da radiação solar através da atmosfera de Vénus é muito ténue, sendo que apenas cerca de uma parte em cem mil da radiação solar total terá essa informação, o que implicou a necessidade de um tempo muito longo de observação por parte do telescópio espacial Hubble. 


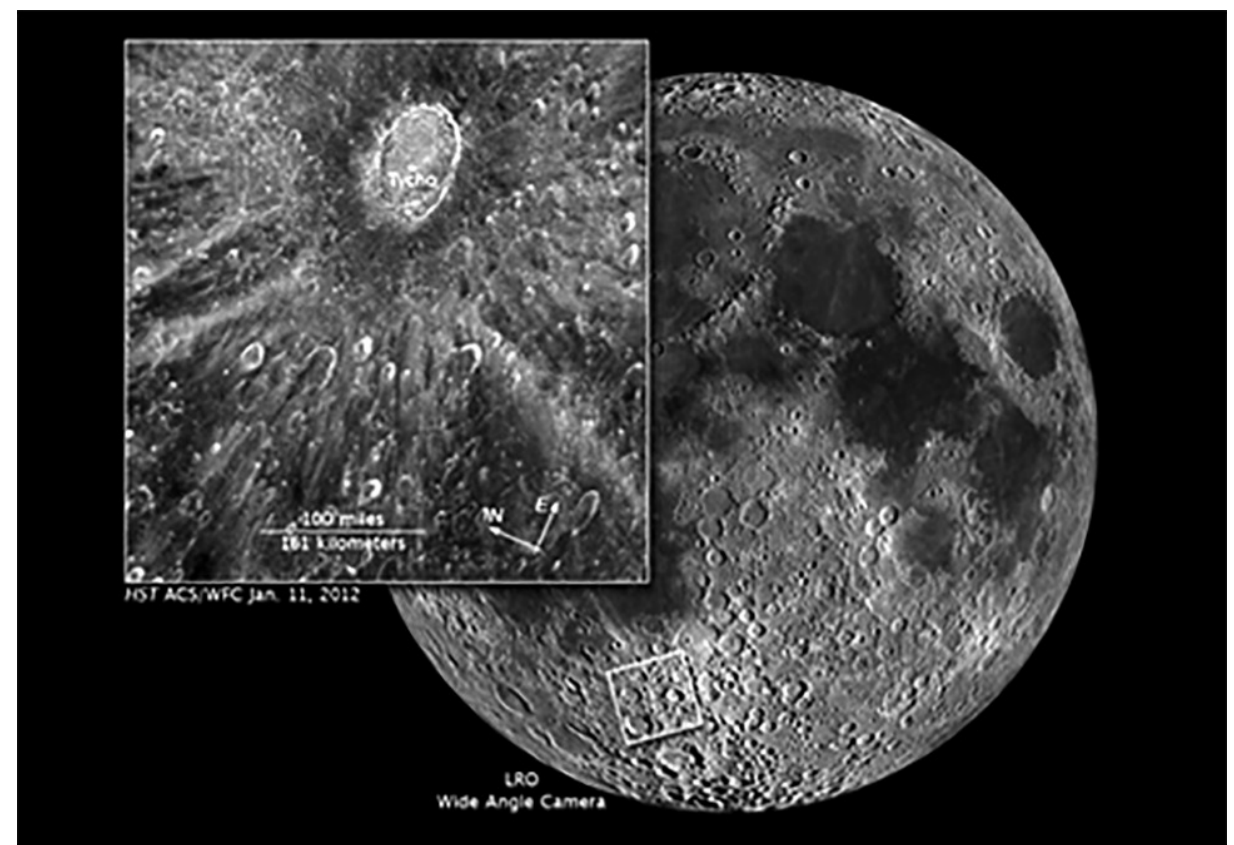

Figura 2 - Posição da região da Lua a ser utilizada como espelho durante o trânsito de Vénus de 2012. Imagem: annesastronomynews.com/hubble-to-use-moon-as-mirror-to-see-venus-transit/; créditos da imagem: NASA/ESA e Z. Levay (STScI).

A assinatura espectral da transmissão da radiação solar através da atmosfera de Vénus é muito ténue, sendo que apenas cerca de uma parte em cem mil da radiação solar total terá essa informação, o que implicou a necessidade de um tempo muito longo de observação por parte do telescópio espacial Hubble.

Uma vez que os trânsitos de Vénus, vistos a partir da Terra, são acontecimentos muito raros (o próximo só irá ocorrer em 2117), houve a necessidade de planificar cuidadosamente esta observação. Uma das preocupações passou por conseguir apontar o telescópio espacial Hubble com precisão para a mesma região da Lua durante sete horas, antes, durante e após o trânsito se completar. Além das dificuldades inerentes devido à órbita do próprio telescópio espacial em torno da Terra, a precisão do apontamento e subsequente acompanhamento (tracking) levantavam algumas dúvidas sobre a eficácia máxima que seria possível atingir. De facto, foi a questão do acompanhamento temporal que acabou por levantar problemas à reconstrução da frente de onda da radiação solar refletida pela Lua e que acabou por inviabilizar parte da investigação ulterior ao trânsito de Vénus baseada nesta técnica invulgar de usar a Lua como um espelho.

A Lua foi também usada como espelho para efetuar medições de extrema precisão da distância entre a Terra e a Lua. Tendo isto em mente, astronautas deixaram posicionados alguns refletores na superfície lunar. Contudo, os primeiros esforços para utilizar a reflexão de impulsos laser por estes pequenos espelhos foram infrutíferos para efetuar as ambicionadas medições de elevada precisão da distância Terra-Lua baseados no tempo que o sinal leva a percorrer o caminho de ida e volta em relação ao emissor laser posicionado no Havai. É de salientar a extrema precisão conseguida quando se utilizou um telescópio no observatório do monte Haleakala (ilha de Maui, Havai): a medição dos mais de 384 mil quilómetros que a Lua dista da Terra foi efetuada com um erro inferior a $2 \mathrm{~cm}$.
Com este tipo de medições de alta precisão passou a ser possível estudar a variabilidade da rotação terrestre à escala temporal do dia, assim como as pequenas oscilações da rotação terrestre em torno do seu eixo de rotação [1]. A compreensão e análise das forças responsáveis por estes movimentos do planeta Terra é essencial para entender a génese dos sismos de grande magnitude.

A partir de observatórios na Terra é feita a emissão de impulsos laser de período muito curto, de aproximadamente 200 trilionésimos de segundo, durante o qual a luz move-se cerca de 4 centímetros, até serem atingidos espelhos deixados na Lua por Neil Armstrong e Edwin Aldrin (em 1969 durante a alunagem da missão Apollo 11) e nas subsequentes missões Apollo 14 e 15, ou instalados nos robôs deixados na Lua pelas missões lunares da União Soviética. Após reflexão nestes espelhos na Lua, a radiação é redirecionada para a Terra onde é captada por telescópios dedicados a este projeto. A utilização deste método baseado na reflexão de curtos impulsos laser na superfície lunar permite o estudo dos pequenos movimentos da posição da Lua devido a efeitos gravitacionais subtis gerados no quadro da teoria da relatividade geral.

Durante a missão LCROSS foi obtido o espetro da Terra refletido na Lua, desde o infravermelho até ao ultravioleta, o qual foi comparado com o modelo espectral predito pelo VPL 3D [2]. Nesse estudo tentou-se verificar se o brilho dos oceanos terrestres, e a sua dependência espectral, podiam ser visíveis no espetro terrestre refletido no regolito lunar (camada de material rochoso não consolidado que cobre o leito rochoso e que é consequência do impacto de meteoritos). O modelo espectral 3D VPL foi também usado para explorar a possibilidade de detetar luas em torno de exoplanetas de tipo terrestre, em função do comprimento de onda utilizado e da fase observada [1]. O modelo mostrou que a contribuição espectral de uma exolua no espectro global do exoplaneta (figura 3) a ser estudado era fortemente dependente da fase [2], e que as 

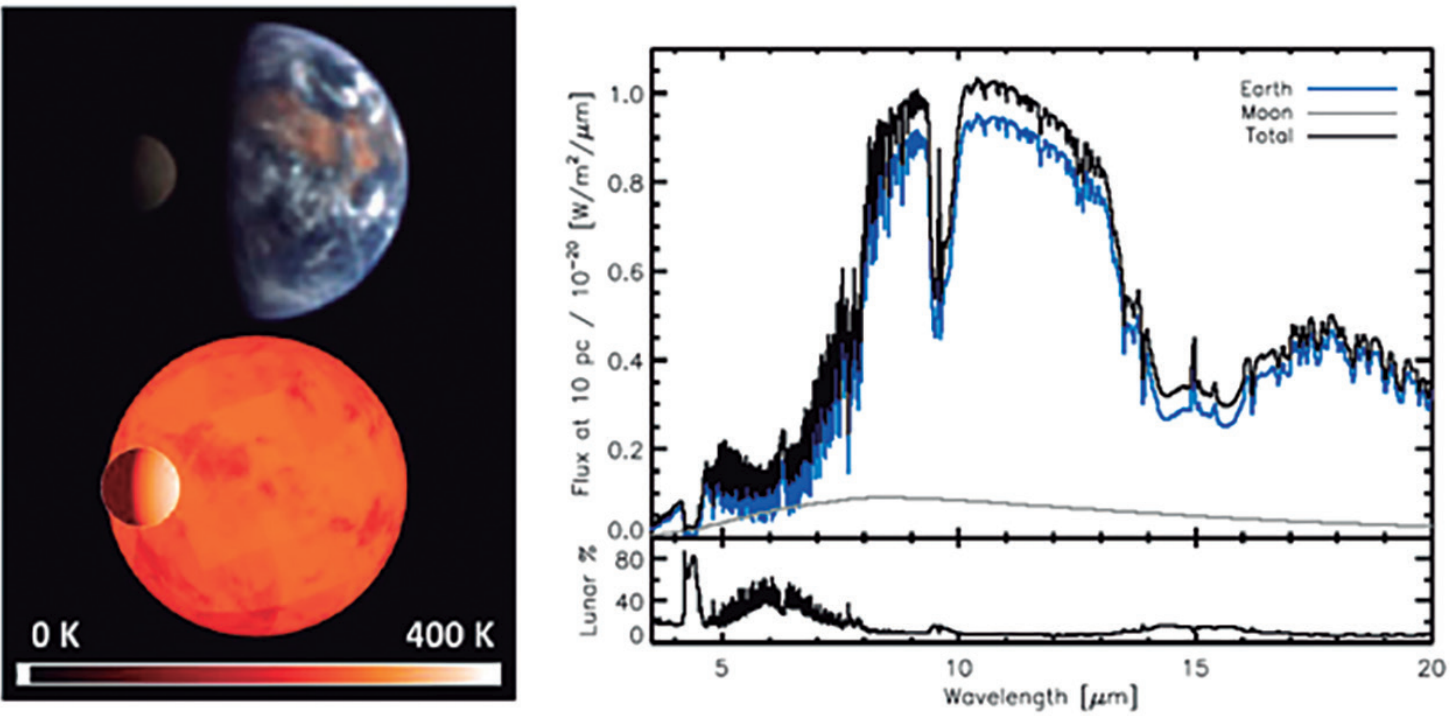

Figura 3 - Técnica para detetar exoluas. Na figura vemos uma imagem em cor verdadeira do sistema Terra-Lua obtida pela missão EPOXI (NASA). O gráfico à direita mostra os espetros correspondentes ao fluxo da Lua a 10 parsecs de distância (cinzento), da Terra (azul) e o espetro combinado (preto) [3].

hipóteses de uma deteção positiva de uma exolua aumentavam significativamente na análise das bandas de absorção relativas ao dióxido de carbono no espetro do exoplaneta em causa [2].

A refletância do regolito lunar foi modelizada usando dados do espetrómetro de interferência de imagem (IIM) a bordo de um orbitador lunar (Chang'e 1), o que levava em conta, para além da composição dos minerais, fatores ligados ao ambiente local. Os modelos prévios exploravam quer o modelo de transferência radiativa, quer modelos de ótica geométrica. $\mathrm{O}$ estudo aqui referido usou a convolução associada aos diversos fatores, como sejam a reflexão topográfica do solo lunar a larga escala e o cálculo da intensidade da luz refletida devido ao efeito da dispersão da radiação no interior das partículas do solo lunar. Este novo método combina técnicas de Monte Carlo para as riscas espectrais com o modelo de Hapke's [4], onde são considerados tanto os efeitos de larga escala como os de microescala para modelizar, com maior precisão, a refletância do regolito na superfície lunar. A aplicação deste modelo permitiu reconstruir a frente de onda refletida pela superfície lunar após a remoção da influência da topografia lunar [4].

Um estudo, desta vez sobre a medição de alta precisão da irradiância da Lua, foi efetuado por Cramer em 2013 [5]. Com a incerteza na irradiância espectral medida abaixo de $1 \%$ entre os 420 e os 1000 nm, é possível estudar padrões climáticos ligados à presença de gelos, neve e aerossóis e à presença de vegetação. Esta técnica torna possível usar a irradiância lunar como um calibrador padrão para observações a partir de satélites e permite a validação de algoritmos de estudo atmosférico.

Revertendo um pouco a abordagem deste artigo, vamos agora considerar a luz refletida e emitida pela Terra e captada na Lua. Este método, ainda em desenvolvimento, pretende desenvolver técnicas para detetar sinais de vida em exoplanetas. Numa primeira fase, este método será implementado, testado e modelizado no sistema Terra-Lua.

Pela primeira vez, astrónomos conseguiram detetar sinais de vida e de habitabilidade da Terra a partir da Lua
[6]. A deteção de bio-assinaturas neste caso de estudo é na verdade um balão de ensaio onde podem ser otimizados os métodos a serem utilizados na pesquisa e deteção de vida em exoplanetas pertencentes a sistemas estelares longínquos [7].

Já foram equacionados vários padrões a detetar que estão relacionados com a vida, como nós a conhecemos. Desde as bandas espectrais típicas da presença de clorofila ou de outros pigmentos naturais até à presença de elementos químicos em desequilíbrio na atmosfera e que podem ser associados como bio-marcadores [6]. Isto já foi feito e estudado a partir das observações da sonda Galileo (NASA), que durante o seu caminho em direção a Júpiter realizou manobras de assistência gravítica em torno da Terra, tirando partido da sua aproximação ao nosso planeta para efetuar observações como as referidas com o intuito de detetar evidências da presença de vida na Terra.

O método de separar a luz proveniente de um exoplaneta da luz proveniente da sua estrela hospedeira assenta em técnicas polarimétricas. Visto que a luz refletida está, em geral, polarizada, é possível separar a radiação proveniente das duas fontes: exoplaneta e estrela-mãe. Assim, a luz proveniente da Terra que vai até à Lua, e depois ricocheteia de regresso à Terra ao ser refletida na superfície lunar, é analisada em termos polarimétricos e permite detetar componentes da luz que podem ser indicadores da presença de vida na Terra [8].

A partir de observações obtidas com o Very Large Telescope (ESO), foram efetuadas medições da intensidade da luz polarizada proveniente da Lua, como descrito antes, e usando técnicas de espetropolarimetria foram detetadas evidências da presença de clorofila e de oceanos na Terra.

Como vimos, o estudo da luz refletida pela Lua tem abordagens multifacetadas. Por um lado, podemos captar a luz transmitida durante um trânsito planetário e assim estudar a "impressão digital" da atmosfera planetária, "impressa" ao ser atravessada pela radiação da estrela-mãe. Esta técnica, ainda em desenvolvimento, pode ser usada no sistema solar (caso do trânsito de Vénus), na caracterização 
das atmosferas de exoplanetas ou no estudo da presença de bio-assinaturas presentes na radiação transmitida através das atmosferas planetárias. Por outro lado, usar a Lua como um espelho da Terra possibilita o estudo aprofundado das variações gravimétricas do sistema Terra-Lua.

\section{Referências}

[1] T. Robinson, V.S. Meadows, D. Crisp, D. Deming, M.F. A'Hearn, D. Charbonneau, T.A. Livengood, S. Seager, R.K. Barry, T. Hearty, T. Hewagama, C.M. Lisse, L.A. McFadden, D.D. Wellnitz, Astrobiology 11 (2011) 393-408.
[2] T.D. Robinson, Earth and Planetary Astrophysics (2014) arXiv: 1511.03288.

[3] T.D. Robinson, Astrophys. J. 741 (2011) 51.

[4] U.-H. Wong, Y. Wu, H.-C. Wong, Y. Liang, Z. Tang, The Scientific World J. (2014) article ID 457138.

[5] C. Cramer, K.R. Lykke, J.T. Woodward, A.W. Smith, J. Res. Natl. Inst. Stand. Technol. 118 (2013) 396-402.

[6] M.F. Sterzik, S. Bagnulo, E. Palle, Nature 483 (2012) 64-66.

[7] C. Sagan, W.R. Thompson, R. Carlson, D. Gurnett, C. Hord, Nature 365 (1993) 715-721.

[8] C.U. Keller, Nature 483 (2012) 38-39.

\section{Atualidades CiEntíficas}

\section{Nova classe de ligandos macrocíclicos}

A conceção e síntese de recetores macrocíclicos é um dos principais desafios na área da química supramolecular. Estes sistemas possuem muitas aplicações, nomeadamente na complexação seletiva de espécies iónicas e neutras, na química medicinal (transporte de fármacos) e em síntese (como catalisadores de transferência de fase). As propriedades complexantes dependem do tamanho da cavidade, do tipo de heteroátomos presentes no anel, dos grupos funcionais existentes, etc. Estruturas baseadas em hidratos de carbono têm sido estudadas devido à sua capacidade de reconhecimento de enantiómeros. Até agora, praticamente só monossacarídeos têm sido usados para a síntese de estruturas macrocíclicas para reconhecimento quiral e pouca atenção tem sido dada a macrociclos com dissacarídeos (ou oligossacarídeos) fazendo parte do anel.

Investigadores da Academia Polaca das Ciências de Varsóvia reportaram a síntese dos primeiros criptandos com unidades de sacarose. Foram usadas duas metodologias de síntese, uma partindo de uma hexa-O-benzilsacarose (um diol) com introdução de uma unidade macrocíclica adicional que liga as posições terminais e outra usando uma penta-O-benzilsacarose (um triol). A segunda via mostrou ser mais promissora pois possibilita a obtenção de estruturas com cavidades de diferentes tamanhos usando reagentes adequados.
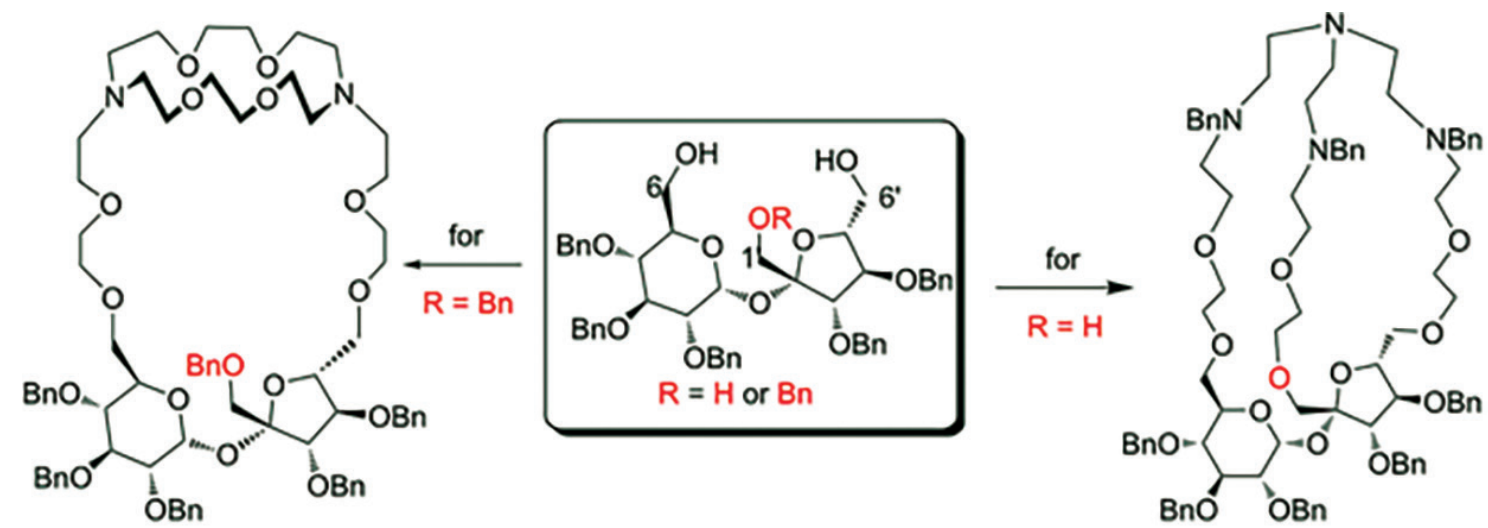

\section{Fonte:}

New Class of Macrocyclic Derivatives,https://www.chemistryviews.org/details/news/11126892/New_Class_of_Macrocyclic_Derivatives.html (Acedido em 26/01/2019)

P. Sokołowska, M. Kowalski, S. Jarosz, Beilstein J. Org. Chem. 15 (2019) 210-217.

Paulo Mendes (pjgm@uevora.pt)
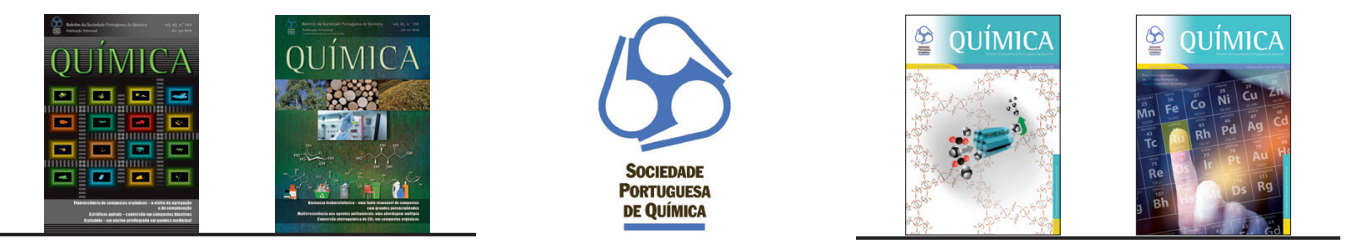